\title{
A Pilot Study to Compare the Standardized Patient's Perception of Empathy Among the American Medical Graduates and International Medical Graduates Applying for Residency Training in the United States
}

Mukaish Kumar ( $\square$ mkmkd@health.missouri.edu )

University of Missouri

Raghav Govindarajan

University of Missouri

\section{Research Article}

Keywords: Empathy, American Medical Graduates, International Medical Graduates, Jefferson Scale of Empathy, Neurology

Posted Date: April 6th, 2021

DOl: https://doi.org/10.21203/rs.3.rs-374955/v1

License: (1) This work is licensed under a Creative Commons Attribution 4.0 International License.

Read Full License

Version of Record: A version of this preprint was published at RRNMF Neuromuscular Journal on March 11th, 2022. See the published version at https://doi.org/10.17161/rrnmf.v3i1.15698. 


\section{Abstract}

\section{Background:}

Empathy is an essential ingredient of patient-centered care. Traditional neurology clerkship does not provide a structured way to teach, evaluate and inculcate the virtue of empathy among our medical students while dealing with various complex neurological conditions. We designed an innovative Objective Structured Clinical Evaluations (O.S.C.E.S) entitled as Empathetic Neurological Care (ENC) O.S.C.E.s as a part of clerkship evaluation to assess empathy among American Medical Graduates (A.M.G.s) and International Medical Graduates (I.M.G.S) and establish the need of training of empathy skills to future professionals.

\section{Study Objective:}

We aim to illustrate the model of Empathetic Neurological Care (ENC) O.S.C.E. \& to report the comparative analysis of empathy scores among the A.M.G.s and I.M.G.s.

\section{Methods:}

This is a pilot study comparing empathy among A.M.G.s and I.M.G.s, measured by the Standardized Patients (SPs) using the Jefferson Scale of Empathy (7-point Likert type scale) during pre-designed ENCOSCEs. The proposed curriculum included complex neurological cases involving breaking bad news (e.g., delivering the diagnosis of A.L.S.), opioid addiction counseling, disclosing medical error (stroke), and explaining the diagnosis of non-epileptic seizures.

\section{Results:}

12 students (6 AMGs, 3 Males/ 3 Females and 6 IMGs 4 Males/2 Females) completed the OSCE. A.M.G.S scored higher in empathy scores graded by S.P.s than I.M.G.s $(P=0.0004)$.

Conclusion: A.M.G.s scored higher empathy as compared to I.M.G.s by the S.P.s during ENC-OSCEs. We highlight the importance of focused empathy training with assessment during neurology clerkship rotations for A.M.G.s \& the need of formal curricular training as a part of the orientation program at the beginning of residency training for I.M.G.s.

\section{Background:}

Empathy is an essential ingredient of patient-centered care, the cornerstone of medical practice ${ }^{1}$. Physician's empathy positively impacts patient safety by providing a better patient outcome, stronger physician-patient relationship, greater patient satisfaction, \& better quality of healthcare ${ }^{2,3,4}$. Empathy in the clinical context is defined as "a predominantly cognitive attribute that involves an understanding of experiences, concerns, and perspectives of the patient, combined with a capacity to communicate this understanding and an intention to help ${ }^{5}$. 
Realizing the importance of the cultivation of professional attitude and essential communication skill of expressing empathy in tomorrow's physicians, the medical schools and health institutions across the world are increasingly focusing on developing a curricular communication training 6,7,8. 'Being compassionate' is one of the seven learning objectives proposed by the association of American medical college as a part of the Medical School Objectives Project (M.S.O.P.) while training the medical graduates in the United States ${ }^{9}$.

The physicians who receive medical education from the medical schools outside the United States and Canada, commonly referred to as International medical graduates (I.M.G.S) are an integral part of healthcare in the U.S.A. I.M.G.s form around one-quarter of physicians in training and practicing physicians in the United States ${ }^{10}$. I.M.G.s play a vital role in the United States healthcare as well as graduate medical education (G.M.E.) by adding diversity to the healthcare system, contributing to the physician workforce $\&$ by serving in underserved areas ${ }^{11}$. With the increased number of residency positions of primary care-specialties in recent years, there is increasing opportunity for I.M.G.s to pursue their career in the United States. Neurology is one of the specialties with the most significant percentage (37\%) of I.M.G.s ${ }^{11}$.

To be eligible to apply for the residency training in the United States, both A.M.G.s and I.M.G.s undergo the same evaluation process (U.S.M.L.E.) where communication \& interpersonal skills (C.I.S.) are an integral part of clinical skill evaluation. Even after succeeding in these evaluation steps, I.M.G.s still face challenges during cross-cultural communication in practice ${ }^{12}$. Although there is little known about empathy and the pertinent barriers I.M.G.s face during the cultural transition, we believe that focused training of I.M.G.s as they enter into residency training will be a great initiative to enhance and sustain empathy in tomorrow's physician-workforce of the United States.

Traditional neurology clerkship does not provide a structured way for us to teach, evaluate and inculcate the virtue of empathy among our medical students while dealing with various complex neurological conditions. To establish the need of training future professionals regarding empathy skills while providing wholesome patient-centered care, we designed an innovative Objective Structured Clinical Evaluations (O.S.C.E.S) model as a part of neurology clerkship entitled as Empathetic Neurological Care (ENC) O.S.C.E.S, and we conducted a pilot study to compare empathy among A.M.G.s and I.M.G.S.

\section{Methods:}

The ENC-OSCEs were developed by the clerkship director in consultation with experts in each neurological subspecialty. Four pilot O.S.C.E.s focusing on delivering bad news (A.L.S. diagnosis), counseling of nonepileptic seizure, counseling opioid use in headache patient, and disclosing medical error (stroke) were chosen based on the variety and complexity of cases. Cases were built from real-life clinical encounters. The ENC OSCEs cases have been offered to both third (M3) and fourth (M4) year medical students (A.M.G.s) as a part of routine clerkship evaluation. We encouraged I.M.G.s who were working as clinical researchers in our department with a plan of residency training application to participate in the O.S.C.E.S 
to practice their clinical skills. Both A.M.G.s and I.M.G.s were blinded about the empathy evaluation to minimize the social desirability bias. Characteristics of the A.M.G.s and I.M.G.s are included in Table:1. All the participants were given handouts about the patient scenario and the expected checklist at the beginning of the clerkship. A didactic session focusing on patient-centered care was done, and the O.S.C.E.s were typically held in the middle of the clerkship just before the mid-block feedback.

Participants were encouraged to practice with their peers by exchanging the roles as physicians/S.P and get the evaluation with constructive feedback from each other using the assessor checklists, including the empathetic statements \& nonverbal empathetic expressions before actual O.S.C.E.s. Our emphasis with the O.S.C.E.s was for students to focus on demonstrating empathy and not on history and neurological exams, which were being taught and assessed by the traditional means. Once the O.S.C.E.s were built, the clerkship director trained the standardized patients (SPs) in different O.S.C.E. scenarios. Patients/families with these conditions were invited to talk with S.P.s to help with their role play. We trained four different standardized patients in all the O.S.C.E. scenarios and have used the four S.P.S throughout our O.S.C.E. encounters. S.P.s encountered \& evaluated three students each. Each session lasted for $15 \mathrm{~min}$. Before the O.S.C.E., both the A.M.G.s and I.M.G.s were given a checklist of items to discuss and a brief review of medical literature on their ENC-OSCE cases. The evaluations were collected from the Standardized patients (SPs) immediately after each encounter which was then compared for A.M.G.s v/s I.M.G.s.

\section{Implementation method:}

The S.P.s evaluated students using the Jefferson Scale of Empathy-Student (JSE-S). The J.S.E. is a validated tool to measure empathy in the setting of medical education and patient-centered care. It includes 20 items; each answered on a 7-point Likert scale (1 indicating "strongly disagree" and seven indicating "strongly agree") with a possible score ranging from 20-140 ${ }^{13}$.

The evaluation by S.P.s during the O.S.C.E.s was used for both formative and summative evaluation. The feedback from S.P.s was done immediately after the O.S.C.E., and the comments from S.P.s were included in the faculty evaluation of the student. These comments have been a part of the student's M.S.P.E.

Table: 1

Baseline characteristics: 


\begin{tabular}{|lllll|}
\hline No & Age & Gender & AMG & IMG \\
\hline 1 & 23 & F & N & Y \\
\hline 2 & 24 & F & N & Y \\
\hline 3 & 24 & M & N & Y \\
\hline 4 & 27 & M & N & Y \\
\hline 5 & 25 & M & N & Y \\
\hline 6 & 24 & M & N & Y \\
\hline 7 & 28 & M & Y & N \\
\hline 8 & 25 & M & Y & N \\
\hline 9 & 40 & M & Y & N \\
\hline 10 & 26 & F & Y & N \\
\hline 11 & 31 & F & Y & N \\
\hline 12 & 28 & F & Y & N \\
\hline Abbreviations: F=Female, M=Male, Y=Yes, N=No. \\
\hline
\end{tabular}

\section{Results:}

In our study, 12 students completed the O.S.C.E. The Jefferson empathy score of every A.M.G and I.M.G is included in Table 2. The average age of A.M.G. was 29.7 (range 25-40) and, that of I.M.G. was 24.5 (range 23-27). A.M.G.s scored higher in empathy expression than I.M.G.s $(110 \pm 8.9 \mathrm{v} / \mathrm{s} 81.7 \pm 9.8 ; P=0.0004)$ graded by S.P.s using J.S.E.

Table: 2 


\begin{tabular}{|llllll|}
\hline No & Age & Gender & AMG & IMG & Jefferson empathy score \\
\hline 1 & 23 & F & N & Y & 80 \\
2 & 24 & F & N & Y & 80 \\
3 & 24 & M & N & Y & 100 \\
4 & 27 & M & N & Y & 70 \\
\hline 5 & 25 & M & N & Y & 80 \\
\hline 6 & 24 & M & N & Y & 80 \\
\hline 7 & 28 & M & Y & N & 120 \\
\hline 8 & 25 & M & Y & N & 110 \\
\hline 9 & 40 & M & Y & N & 100 \\
\hline 10 & 26 & F & Y & N & 120 \\
\hline 11 & 31 & F & Y & N & 110 \\
\hline 12 & 28 & F & Y & N & 100 \\
\hline Abbreviations: F=Female, M=Male, Y=Yes, N=No. & \\
\hline
\end{tabular}

\section{Discussion:}

Empathy in the clinical context is referred to as 'clinical empathy,' the term which expands beyond merely 'being in someone's shoes' or 'acknowledging feelings of others' and have cognitive, emotive, behavioral, and moral domains ${ }^{14,15}$. The cognitive attribute of empathy in contrast to sympathy (intense emotions) makes it a skill that can be learned, taught, and assessed ${ }^{16}$. In a six-year longitudinal study of medical students in Japan, the targeted medical education program with the emphasis on communication skills training for empathy development has been proven to improve the quality of patient care significantly ${ }^{17}$. Engaging medical students in focused communication skills training has enhanced empathy in several other research studies ${ }^{18}$. Medical professionalism will be fragmentary without empathy training.

Empathy in medical students represents the future of doctor-patient relationships and compassionate care during residency training \& clinical practice ${ }^{19}$. The curricular activity of the art of expressing clinical empathy towards the patients has been undervalued in medical education ${ }^{20}$. The primary emphasis of clerkship training used to be only on developing clinical thinking by achieving expertise in history taking and physical examination. Unfortunately, empathetic communication and rapport building are perceived 
as less important skills to learn than the medical students' clinical skills as they progress to the higher level of clinical training during medical school ${ }^{21}$.

American Board of internal medicine (A.B.I.M.) has recommended the training of empathy and humanistic qualities as an integral part of graduate medical education during the first and second year of medical school ${ }^{22}$. Most of the students swore by the Hippocratic Oath as they enter this noble profession of medicine with the goal to serve and ease human sufferings. In an empiric study conducted at the Jefferson medical school, Hojat et al. have reported that empathy among the medical students gradually declined as they proceeded to a higher level of medical education during medical school ${ }^{23}$. Results of the systemic review of 11 studies by Neumann et al.; to evaluate empathy in medical students has also demonstrated a significant decrease in empathy during medical school in 3 longitudinal and six crosssectional studies ${ }^{24}$. Ironically, the need of empathy from physicians in training is crucial at the point of bed-to-bench transition during the third year when they interact with patients and their families.

Redesigning the curriculum to change the focus of this training from the first two years to the last two years of training has been focused on the recent years.Also, understanding the underlying causes of the decline in medical student's empathy and addressing these issues is a crucial part of medical education. There is limited insight available regarding the factors responsible for this conflicting behavioral change during the transition from pre-clinical years to clinical clerkships. As reported in the literature, distress in the form of burnout due to study and work overload, depression, low self-esteem, etc., is considered as a major cause of the empathy decline in medical students ${ }^{25,26,27,28}$. Other reasons for lack of empathy in medical professionals include biographical experiences, personality traits, lack of role-models, improper learning environment, ill-treatment by superiors, \& social support, etc ${ }^{29,30,31,32,33}$. A survey was done to understand the medical student's perception of factors affecting empathy during medical education. The results showed that professional growth-promoting clinical experiences and mentoring were the top most important medical students' factors rated by the medical students ${ }^{34}$.

Medical students can thrive and learn to achieve clinical expertise but creating a strong \& trustworthy doctor-patient relationship is an art every medical student must learn. As with the clinical skills, the 'use it or lose it' principle is also applicable to the medical professionalism attributes such as empathy. Medical students can be trained via lectures, simulations, discussions of video clips, reviews of their clinical encounters, experiential learning, focused empathy training, role-playing, creative arts, poetry writing, literature reviews, and dramas ${ }^{23}$. Some of the approaches tried by medical educators to reinforce and maintain the practice of empathy among undergraduate medical students have been found to significantly effective ${ }^{35}$. Training and evaluating the medical students in providing holistic, patientcentered care during clerkships assures that what learned in the classrooms will be translated into compassionate bedside care. In addition to succeeding in providing patient-centered care, physicians can also reap the benefits of practicing empathetic skills. Studies have shown a significant reduction in burnout, increased professional satisfaction, and well-being among those who express empathy in their practice $^{35,36,37}$. 
With globalization in the modern era, physicians and patients from diverse ethnocultural backgrounds encounter with each other more frequently. Approximately $24 \%$ of residents and $26 \%$ of physicians from various specialties practicing in the United States are I.M.G.s ${ }^{38}$. International medical graduates face several communication barriers as they switch between different cultural environments. In a qualitative analysis of communication barriers perceived by I.M.G.S, Dorgan et al. have reported two broad categories -education-related barriers and Interpersonal barriers ${ }^{39}$. Educational barriers include sciencefocused training without emphasizing the physician-patient communication and lack of formal communication training, and interpersonally related barriers entail unfamiliar dialects, new power dynamics, and different rapport-building expectations ${ }^{39}$. Forming a substantial part of the U.S. physicians' workforce, I.M.G.s training concerning empathy should be equally emphasized while adopting empathy enhancing interventions in the graduate medical education (G.M.E.) curriculum to optimize patient-centered care.

Several complex neurological conditions affect the quality of life of patients. Patients and their families rely on physicians to exchange information, decision-making, and emotional support during these tough periods of their lives. Breaking bad news such as diagnosing fatal diseases such as Amyotrophic Lateral Sclerosis, educating patients about their addiction to opioids, declaring the diagnosis of non-epileptic seizures, and disclosing the medical errors, affect patients and families psychosocially. These challenging issues can significantly influence the doctor-patient relationship in either way. However, accepting these challenges as the opportunities to express empathy can strengthen the doctor-patient relationships while providing patient-centered care. Learning and practicing how $\&$ when to provide empathetic care by communicating effectively, the medical students can deal comfortably with the reallife complex clinical scenarios in daily practice. With this philosophy, we designed the ENC-OSCES specifically for complex neurological conditions.

The O.S.C.E.s are used for both formative and summative evaluation of the students. The feedback from the O.S.C.E.s (including feedback from standardized patients) will be a part of the medical school performance evaluation (M.S.P.E.). Our pilot study is a primer to show the impact of educational intervention during the neurology clerkship on S.P.s' perception of physician's empathy and the need of focused intervention strategies for I.M.G.s as they enter into neurology residency training in our institute.

We found that both M4 and M3s performed better than international graduates in terms of empathy scores as perceived by standardized patients. Student feedback on the ENC OSCE was highly positive, ranging from 'humbling experience' to 'highlight of clerkship.' Randomly chosen videos of different O.S.C.E. encounters were reviewed with patients and their families who have repeatedly validated its authenticity and its reflection of a real-life encounter, with some saying that they felt it was them as the S.P.s in the video. The school of medicine highlighted the opioid counseling O.S.C.E. as one of the educational tools being developed/taught to students in combating opioid addiction/epidemic in its L.C.M.E. report. To our knowledge, our study is unique in the comparative evaluation of empathy among the A.M.G.s and I.M.G.s as perceived by standardized patients \& scored on J.S.E. utilizing an innovative ENC-OSCEs model. 
We believe that sustaining the skill of empathy or regaining the lost art of medicine during the practice is a challenging but certainly not impossible task for medical educators. The metamorphosis of medical students into compassionate physicians/ caregivers can be achieved through focused training during their clerkship rotation.

\section{Conclusion:}

As seen in our pilot study, A.M.G.s scored higher than I.M.G.s in empathy evaluation by S.P.s. We wish to highlight the importance of a designed curriculum to train and evaluate medical students during their clerkships to inculcate empathy as a professional skill while dealing with complex neurological conditions during neurology clerkship rotations. We also wish to highlight the need of empathy-building training as a part of the orientation program/ residency curriculum explicitly addressing the needs of international medical graduates from diverse ethnocultural backgrounds.

Assessment of empathy by the standardized patients can serve as constructive feedback to the medical students and reinforce the practice of empathy as a second nature. Our ENC-OSCEs model may serve as a promising tool to improve the neurology patient experience.

\section{Future direction:}

Future large-scale studies are needed to validate J.S.E. as a tool to evaluate empathy during medical encounters of complex neurological conditions. We intend to do a large-scale study to direct our attempts to enhance empathy among both A.M.G.S and I.M.G.s as they enter into residency training and eventually the US-physicians workforce. At our institute, the ENC OSCEs will be offered to incoming neurology residents with constructive feedback as a part of their orientation. New O.S.C.E.s on end-of-life discussion in a patient with a massive stroke, telemedicine encounter of a chronic migraine patient, counseling of a patient with Huntington's disease will be added to the ENC OSCEs.

\section{Limitations Of The Study:}

We have conducted this pilot study with a small number of participants, and to establish the effectiveness of our intervention, we intend to do a large-scale study in the future with more number of A.M.G.s and I.M.G.s. The drawback of empathy assessment during O.S.C.E., as reported by Chen et al., maybe a social desirability bias as the participants may exhibit the desired behavior pattern during these O.S.C.E.s. However, we tried to minimize this bias to some extent by blinding the participants about their empathy evaluation by S.P.s. We encouraged them to perform as in their routine clerkship O.S.C.E.s. There are several other factors other than formal training during medical school that attributes to low empathy among the I.M.G.s, such as language proficiency, personality traits, cultural upbringing, attitude, cultural competence, prior clinical and professional experiences in the United States etc. These factors are not addressed in our pilot study. Further study to investigate the factors affecting empathy among I.M.G.s is needed before future empathy training interventions. 


\section{Abbreviations}

Objective Structured Clinical Evaluations (O.S.C.E.s), Empathetic Neurological Care (E.N.C), American Medical Graduates (A.M.G.s), International Medical Graduates (I.M.G.S), Standardized Patients (SPs), Amyotrophic Lateral Sclerosis ( A.L.S), Medical School Objectives Project (M.S.O.P.), Graduate Medical Education (G.M.E.), Jefferson Scale of Empathy (J.S.E.).

\section{Declarations}

\section{- Ethics approval and consent to participate:}

This study was performed under the relevant guidelines and regulations of ethical principles for human studies and approved by the local ethics committee of the University of Missouri I.R.B. Informed consent was obtained from all subjects for participation in the study.

\section{- Consent for publication:}

Not applicable.

\section{- Availability of data and materials:}

The datasets used during the current study are available from Mukaish Kumar ( M.K) and Raghav Govindarajan (R.G) on reasonable request.

\section{- Competing interests:}

The authors have no conflict of interest to report.

\section{- Funding}

This study has no sources of funding to disclose.

\section{- Authors' contributions:}

M.K and R.G involved in designing concepts, literature search, data analysis, writing and in drafting the article. All authors contributed to the manuscript, and R.G. approved the final version of the manuscript.

\section{- Acknowledgements:}

Not applicable.

\section{References}


1. Institute of Medicine (U.S.) Committee on Quality of Health Care in America. Crossing the Quality Chasm: A New Health System for the 21st Century. Washington (D.C.): National Academies Press (U.S.); 2001.PubMed P.M.I.D.: 25057539.

2. Mercer SW, Reynolds WJ. Empathy and quality of care. Br J Gen Pract. 2002; 52(suppl):S9 -S13.

3. Di Blasi Z, Harkness E, Ernst E, Georgiou A, Kleijnen J. Influence of context effects on health outcomes: A systematic review. Lancet. 2001; 357:757-762.

4. Rakel D, Barrett B, Zhang Z, et al. perception of empathy in the therapeutic encounter: Effects on the common cold. Patient Educ Couns. 2011; 85:390-397.

5. Hojat, M., Mangione, S., Nasca, T. J., Cohen, M. J. M., Gonnella, J. S., Erdmann, J. B., et al. (2001). The Jefferson Scale of Physician Empathy: Development and preliminary psychometric data. Educational and Psychological Measurement, 61, 349-365.

6. General Medical Council. Tomorrow's Doctors: Recommendations on Undergraduate Medical Education. London, U.K.: General Medical Council, 1993.

7. Makoul G, Schofield T. Communication teaching and assessment in medical education: an international consensus statement. Patient Educ Couns. 1999; 137:191-5.

8. Association of American Medical Colleges. Medical School Objectives Project, Report III. Contemporary Issues in Medicine: Communication in Medicine. Washington, DC: Association of American Medical Colleges, 1999.

9. Association of American Medical Colleges. Report I: Learning objectives for medical student education-Guidelines for medical school. Acad Med. 1999; 74:13-18. http:// journals.Iww.com/academicmedicine/ Abstract/1999/01001/Learning objectives_ for_medical_student.10.aspx. Accessed April 5, 2011.

10. https://www.ecfmg.org/news/2018/03/16/imgs-show-strong-performance-in-the-2018-match

11. Ranasinghe P.D. International medical graduates in the U.S. physician workforce. J Am Osteopath Assoc. 2015 Apr; 115 (4):236-41. doi: 10.7556/jaoa.2015.047. Review.

12. Boulet JR, McKinley DW, Whelan GP, Van Zanten M, Hambleton RK. Clinical skills deficiencies among first-year residents: Utility of the E.C.F.M.G. clinical skills assessment. Acad Med. 2002; 77 (suppl):S33-S35.

13. Hojat M. Empathy in Patient Care: Antecedents, Development, Measurement, and Outcomes. New York, NY: Springer; 2007.

14. Halpern J. From Detached Concern to Empathy: Humanizing Medical Practice. New York: Oxford University Press; 2001.

15. Benbassat J, Baumal R. What is empathy, and how can it be promoted during clinical clerkships? Acad Med. 2004; 79:832.

16. Drdla S, Löffler-Stastka H (2016) Influence of conversation technique seminars on the doctoral therapeutic attitude in doctor-patient communication. Wien Klin Wochenschr 128:555-559. 
17. Kataoka H, Iwase T, Ogawa H, Mahmood S, Sato M, DeSantis J, Hojat M, Gonnella JS. Can communication skills training improve empathy? A six-year longitudinal study of medical students in Japan. Med Teach. 2018 Apr 22:1-6.

18. Hojat M, Axelrod D, Spandorfer J, Mangione S. 2013. Enhancing and sustaining empathy in medical students. Med Teach. 35:996-1001.

19. Hojat M, Mangione S, Nasca TJ, Gonella JS, Magee M. Empathy scores in medical school and ratings of empathic behavior in residency training 3 years later. J Soc Psychol. 2005; 145: 663-72.

20. Shapiro H, Curnan M, Peschel E, St James D. Empathy and the practice of medicine: beyond pills and the scalpel. 1993; New Haven: Yale University Press.

21. General Medical Council. Tomorrow's Doctors: Recommendations on Undergraduate Medical Education. London, U.K.: General Medical Council, 1993.

22. Evaluation of humanistic qualities in the internist. Ann Intern Med. 1983 Nov; 99(5):720-4.

23. Hojat, M., Mangione, S., Nasca, T. J., Cohen, M. J. M., Gonnella, J. S., Erdmann, J. B., et al. (2001). The Jefferson Scale of Physician Empathy: Development and preliminary psychometric data. Educational and Psychological Measurement, 61, 349-365.

24. Neumann M, Edelhäuser F, Tauschel D, Fischer MR, Wirtz M, Woopen C, Haramati A, Scheffer C. Empathy decline and its reasons: a systematic review of studies with medical students and residents. Acad Med. 2011 Aug; 86(8):996-1009. doi: 10.1097/ACM.0b013e318221e615. Review.

25. Thomas MR, Dyrbye LN, Huntington JL, et al. How do distress and well-being relate to medical student empathy? A multicenter study. J Gen Intern Med. 2007; 22:177-183.

26. Rosen IM, Gimotty PA, Shea JA, Bellini LM. Evolution of sleep quantity, sleep deprivation, mood disturbances, empathy, and burnout among interns. Acad Med. 2006; 81:82-85.

http://journals.Iww.com/ academicmedicine/Fulltext/2006/01000/ Evolution_of_Sleep_Quantity_Sleep_Deprivation.20.aspx. Accessed April 5, 2011.

27. Shanafelt TD, West C, Zhao X, et al. Relationship between increased personal well-being and enhanced empathy among internal medicine residents. J Gen Intern Med. 2005; 20: 559 - 564.

28. Bellini LM, Shea JA. Mood change and empathy decline persist during three years of internal medicine training. Acad Med. 2005; 80:164 - 167. http://journals.Iww.com/academic medicine/Fulltext/2005/02000/Mood_Change_and_Empathy_Decline_Persist_during.13. aspx. Accessed April 5, 2011.

29. Neumann M, Bensing J, Mercer SW, Ernstmann N, Pfaff H. Analyzing the "nature" and "specific effectiveness" of clinician empathy: A theoretical overview and contribution towards a theory-based research agenda. Patient Educ Couns. 2009; 74:339 - 346.

30. McManus IC, Keeling A, Paice E. Stress, burnout and doctors' attitudes to work are determined by personality and learning style: A twelve-year longitudinal study of U.K. medical graduates. BMC Med. 2004; 2:29.

31. Newton B, Barber L, Clardy J, Cleveland E, O'Sullivan P. Is there hardening of the heart during medical school? Acad Med. 2008; 83: 244 - 249. 
32. Stratton TD, Saunders JA, Elam CL. Changes in medical students' emotional intelligence: An exploratory study. Teach Learn Med. 2008; 20: 279 - 284.

33. Melchers MC, Li M, Haas BW, Reuter M, Bischoff L, Montag C (2016) Similar personality patterns are associated with empathy in four different countries. Front Psychol 7:290.

34. Winseman J, Malik A, Morison J, Balkoski V. Students' views on factors affecting empathy in medical education. Acad Psychiatry. 2009 Nov-Dec; 33(6):484-91.

35. Riess H, Kraft-Todd G. E.M.P.A.T.H.Y.: a tool to enhance nonverbal communication between clinicians and their patients. Acad Med. 2014; 89:1108-1112.

36. Kelley JM, Kraft-Todd G, Schapira L, Kossowsky J, Riess H. The influence of the patient-clinician relationship on healthcare outcomes: a systematic review and meta-analysis of randomized controlled trials. PLoS O.N.E. 2014;9: e94207

37. Shanafelt TD, West C, Zhao X, et al. Relationship between increased personal well-being and enhanced empathy among internal medicine residents. J Gen Intern Med. 2005; 20:559-564.

38. Center for Workforce Studies. 2014 Physician specialty Data Book. Washington, DC; Association of American Medical Colleges; November 2014.

39. Dorgan KA, Lang F, Floyd M, Kemp E. International medical graduate-patient communication: a qualitative analysis of perceived barriers. Acad Med. 2009 Nov; 84(11):1567-75. 